\title{
THE EFFECT OF B CHROMOSOMES ON MEIOSIS IN AUTOTETRAPLOID LOLIUM PERENNE
}

\author{
A. J. MACEFIELD* and G. M. EVANS \\ Department of Agricultural Botany, University College of Wales, \\ Aberystwyth SY23 3DD, U.K.
}

Received 8.xii.75

\section{Summary}

The effect of B chromosomes on meiosis in autotetraploid Lolium perenne is such that the frequency of bivalents is increased and that of multivalents decreased quite independently of p.m.c. chiasma frequency. It appears, therefore, that the influence of B's in promoting the association of pairs of chromosomes is much less specific than was hitherto assumed, affecting homologous as well as homoeologous pairing.

\section{INTRODUCTION}

B GHROMOSOMES of Lolium perenne are known to reduce homoeologous chromosome pairing at meiosis in both the diploid and tetraploid (allotetraploid) interspecific hybrid Lolium temulentum $\times$ Lolium perenne (Evans and Macefield, 1972, 1973), and, to a lesser extent, in Festuca arundinacea $\times$ Lolium perenne (Bowman and Thomas, 1973) and in Lolium multiflorum $\times$ Lolium perenne (Evans and Macefield, 1974; Bowman, 1974). The present work is an evaluation of the effect of these same B's in a synthetic autotetraploid of Lolium perenne.

\section{Materials AND MEthods}

The Lolium perenne stock used was based on the diploid population, Ba 8973 from the Welsh Plant Breeding Station. This was originally collected in Algeria and some plants were subsequently found to carry one to three B chromosomes.

Autotetraploids were produced by treatment of young seedlings with 0.2 per cent aqueous colchicine for 3 hours. All seedlings were eventually transferred to soil in pots and grown in an unheated greenhouse until emergence of the inflorescences. Emerging spikes were fixed in Carnoy's solution (ethanol/chloroform/acetic acid) and stored for several months before examination.

Squash preparations of pollen mother cells (p.m.c.'s) at first metaphase of meiosis were made in aceto carmine stain. The distribution and frequency of chiasmata together with the frequency of the various chromosome configurations were scored in 20 p.m.c.'s per plant.

\section{Results}

A total of 24 tetraploid plants were analysed at first metaphase of meiosis. The number, if any, of B chromosomes present in each plant was established

* Present address: Bush Johnsons Ltd., Woodham Mortimer, Maldon, Essex CM9 6SN. 
and the frequency per p.m.c. of quadrivalents, trivalents, bivalents, univalents and chiasmata also recorded. The data are given in table 1 . It is clear that on a single plant basis there is considerable variation in the frequency of the various configuration both between and, to a lesser extent, within classes. An overall pattern does, however, emerge in that tetraploids without B's have more multivalents (quadrivalents and trivalents) and fewer

\section{TABLE 1}

Average frequencies of quadrivalents, trivalents, bivalents, univalents along with chiasma frequency in autotetraploid plants containing $0,2,4$ and $6 B$ chromosomes

\begin{tabular}{|c|c|c|c|c|c|}
\hline \multirow{10}{*}{ OB Class } & Quad. & Triv. (Mult.) & Biv. & Univ. & Chiasma freq. \\
\hline & $1 \cdot 75$ & $1 \cdot 10(2 \cdot 85)$ & $7 \cdot 80$ & $2 \cdot 10$ & $20 \cdot 90$ \\
\hline & $1 \cdot 75$ & $0 \cdot 40(2 \cdot 10)$ & $9 \cdot 25$ & $1 \cdot 30$ & $19 \cdot 40$ \\
\hline & $1 \cdot 20$ & $1.05(2 \cdot 25)$ & $9 \cdot 50$ & 0.95 & $21 \cdot 20$ \\
\hline & $1 \cdot 50$ & $0 \cdot 80(2 \cdot 30)$ & $8 \cdot 90$ & $1 \cdot 80$ & $21 \cdot 05$ \\
\hline & $3 \cdot 30$ & $0.50(3.80)$ & $5 \cdot 90$ & $1 \cdot 20$ & $22 \cdot 40$ \\
\hline & $2 \cdot 25$ & $0.05(2.30)$ & $8 \cdot 90$ & 1.05 & $20 \cdot 95$ \\
\hline & $1 \cdot 50$ & $0 \cdot 15(1 \cdot 65)$ & $10 \cdot 30$ & 0.95 & $21 \cdot 45$ \\
\hline & $1 \cdot 70$ & $0.05(1.75)$ & $9 \cdot 50$ & $2 \cdot 05$ & $20 \cdot 30$ \\
\hline & $2 \cdot 05$ & $0.00(2.05)$ & $9 \cdot 70$ & 0.90 & $22 \cdot 10$ \\
\hline Mean & 1.89 & $0.46(2 \cdot 34)$ & $8 \cdot 87$ & $1 \cdot 37$ & $21 \cdot 08$ \\
\hline \multirow[t]{5}{*}{ 2B Class } & $2 \cdot 15$ & $0.05(2 \cdot 20)$ & $8 \cdot 65$ & 1.95 & $21 \cdot 30$ \\
\hline & $1 \cdot 00$ & $0.00(1.00)$ & $11 \cdot 85$ & $0 \cdot 30$ & $20 \cdot 55$ \\
\hline & $0 \cdot 80$ & $0.10(0.90)$ & $10 \cdot 00$ & $4 \cdot 50$ & $17 \cdot 15$ \\
\hline & 0.85 & $0.10(0.95)$ & $11 \cdot 15$ & $1 \cdot 20$ & $22 \cdot 75$ \\
\hline & 0.95 & $0 \cdot 15(1 \cdot 10)$ & $11 \cdot 65$ & 0.60 & $23 \cdot 95$ \\
\hline Mean & $1 \cdot 15$ & $0.08(1.23)$ & $10 \cdot 74$ & $1 \cdot 71$ & $21 \cdot 14$ \\
\hline \multirow[t]{6}{*}{ 4B Class } & $0 \cdot 70$ & $0 \cdot 00(0 \cdot 70)$ & $12 \cdot 15$ & 0.90 & $21 \cdot 45$ \\
\hline & $2 \cdot 90$ & $0.00(2.90)$ & $7 \cdot 45$ & $1 \cdot 50$ & $21 \cdot 75$ \\
\hline & 0.45 & $0.10(0.55)$ & $12 \cdot 10$ & $1 \cdot 70$ & $22 \cdot 00$ \\
\hline & 0.45 & $0.05(0.50)$ & $12 \cdot 55$ & 0.85 & $21 \cdot 15$ \\
\hline & $1 \cdot 65$ & $0 \cdot 10(1 \cdot 75)$ & $9 \cdot 70$ & $1 \cdot 70$ & $22 \cdot 40$ \\
\hline & $2 \cdot 75$ & $0.05(2.80)$ & $8 \cdot 20$ & $0 \cdot 45$ & $24 \cdot 05$ \\
\hline Mean & $1 \cdot 49$ & $0.05(1.53)$ & $10 \cdot 36$ & $1 \cdot 18$ & $22 \cdot 13$ \\
\hline \multirow[t]{4}{*}{ 6B Class } & 0.50 & $0.00(0.50)$ & $12 \cdot 95$ & $0 \cdot 10$ & $24 \cdot 05$ \\
\hline & $1 \cdot 90$ & $0.10(2 \cdot 00)$ & $9 \cdot 20$ & $1 \cdot 70$ & $21 \cdot 45$ \\
\hline & $1 \cdot 45$ & $0.30(1.75)$ & $9 \cdot 40$ & $2 \cdot 35$ & $18 \cdot 50$ \\
\hline & $0 \cdot 85$ & $0.00(0.85)$ & $11 \cdot 85$ & 0.90 & $22 \cdot 90$ \\
\hline Mean & $1 \cdot 18$ & $0 \cdot 10(1 \cdot 28)$ & $10 \cdot 85$ & $1 \cdot 26$ & $21 \cdot 72$ \\
\hline
\end{tabular}

Figures in brackets are the frequencies of multivalents, i.e. Quadrivalents plus Trivalents.

bivalents than those containing B's. This difference, although not large, is nevertheless significant $(\mathrm{P}=<0.01)$. The number of $\mathrm{B}$ chromosomes present does not appear to alter this pattern as there is no significant variation in either multivalent or bivalent frequency between the B chromosome classes. The pairing pattern at meiosis in tetraploid Lolium, like that in some other autotetraploids, is partly dependent on the cell chiasma frequency (Crowley and Rees, 1968; Simonsen, 1973). The correlation is such that increasing chiasma frequency is normally accompanied by an increase in the number of quadrivalents and a decrease in the number of bivalents. 
In the present investigation there is some evidence (table 1) that plants with B's have a slightly higher chiasma frequency than those without B's, although only those with 4B's are significantly higher $(P=<0 \cdot 05)$. That the lower quadrivalent frequency and higher bivalent frequency in the $\mathrm{B}$ chromosome plants is merely a consequence of variation in chiasma
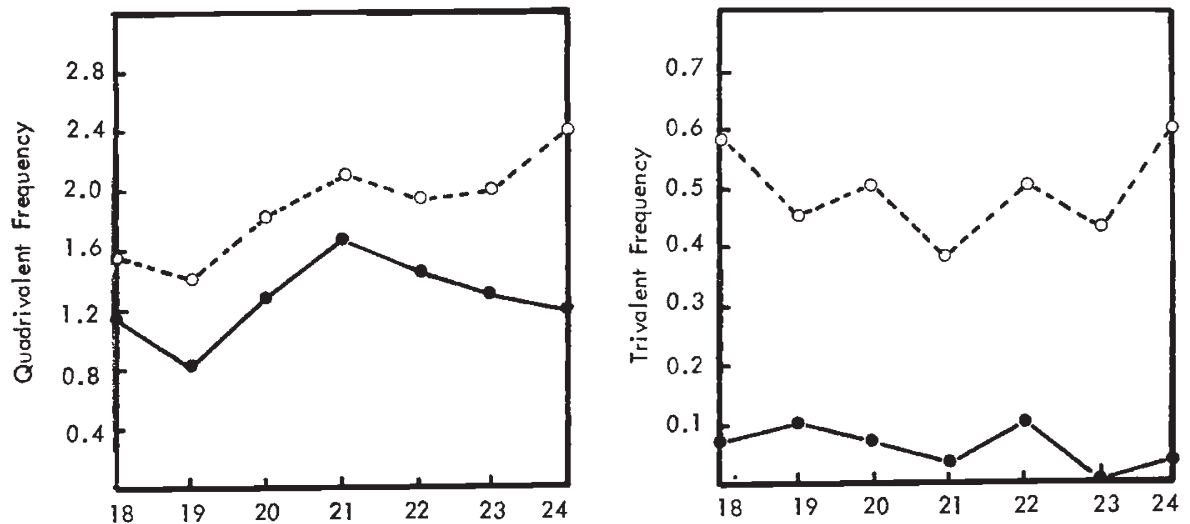

Cell Chiasma Frequency

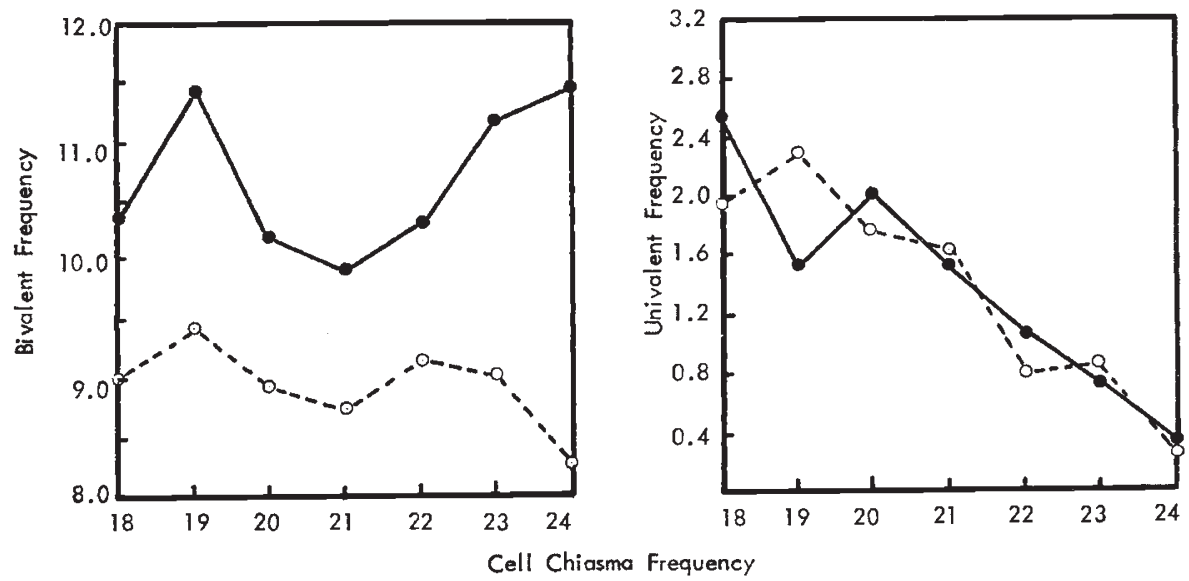

Fig. 1.-The average frequency of quadrivalents, trivalents, bivalents and univalents in pollen mother cells of specific chiasma frequency. $0-\cdots$, Without B's; With B's.

frequency is therefore unlikely. This is confirmed by a comparison of the pairing pattern in p.m.c.'s having identical number of chiasmata (fig. 1). The data for $2 \mathrm{~B}, 4 \mathrm{~B}$ and $6 \mathrm{~B}$ classes have been bulked since a preliminary analysis showed no significant difference in pairing pattern between these classes. Joint regression analyses for each configuration is given in table 2. It is clear from fig. 2 and table 2 that there are consistently fewer quadrivalents and trivalents and more bivalents in p.m.c.'s from B chromosome plants than in those from plants without B's, i.e. the normal autotetraploid. Furthermore, the pattern is essentially the same over the full range of p.m.c. chiasma frequencies as is evident from the lack of a significant difference 
between the slopes of the regression lines for quadrivalents, trivalents and bivalents and the highly significant difference between the means of regression lines for all three configurations. There is no difference in the number of univalents in cells from $\mathrm{B}$ or $\mathrm{OB}$ plants. The conclusion must be that $\mathrm{B}$ chromosomes, even in a newly formed autotetraploid, increase the probability of association of pairs of chromosomes at meiosis. This, of course, is far from complete, as is clearly evident from the data.

TABLE 2

Foint regression analyses of the average frequencies of quadrivalents, trivalents, bivalents and univalents in pmc's of specific chiasma frequencies in autotetraploid plants without and with $B$ chromosomes

\begin{tabular}{lccc} 
& \multicolumn{3}{c}{ Mean squares } \\
\cline { 2 - 4 } $\begin{array}{c}\text { Heterogeneity } \\
\text { of regressions }\end{array}$ & $\begin{array}{c}\text { Heterogeneity } \\
\text { of Means }\end{array}$ & $\begin{array}{c}\text { Error } \\
\text { Quadrivalents }\end{array}$ \\
Trivalents & 0.086 & $1.290 * *$ & 0.063 \\
Bivalents & 0.001 & $0.652 * * *$ & 0.005 \\
Univalents & 0.473 & $11.684 * * *$ & 0.271 \\
$\qquad$ & 0.001 & 0.001 & 0.090 \\
& & & \\
& & &
\end{tabular}

A direct analysis of the distribution of quadrivalents amongst the seven sets of four homologues is not possible in Lolium as the individual sets are indistinguishable at meiosis. An indirect method, first proposed by Hall (1955), can be used to assess whether the reduction in quadrivalent formation due to $\mathrm{B}$ chromosomes is a random effect spread over the whole complement or whether some sets are more likely to form bivalents than others. It is argued that if each set of four homologous chromosomes is equally likely to form quadrivalents then the number of p.m.c.'s with $0,1,2,3-7$ quadrivalents should follow a binomial distribution. Any deviation from the expected distribution is then interpreted as evidence that the probability of quadrivalent formation is not uniform over the seven sets of homologues.

In the present study the quadrivalent frequency of 180 p.m.c.'s from nine $\mathrm{OB}$ plants did not deviate significantly from the expected, assuming a binomial distribution $\left(\chi_{[3]}^{2}=3 \cdot 27, \mathrm{P}=>0 \cdot 3\right)$. This is in agreement with the work of Simonsen (loc. cit.) from a much larger population of cells of autotetraploid L. perenne. Of particular interest, however, is that the quadrivalent frequency of 300 p.m.c.'s from 15 B chromosome plants does not follow a binomial distribution $\left(\chi_{[3]}^{2}=35.42, \mathrm{P}=<0.001\right)$. It appears, therefore, that whereas each of the seven sets of chromosomes are equally capable of forming a quadrivalent in the normal $\mathrm{OB}$ autotetraploid this is not so in the autotetraploids with B's. This analysis still does not identify how many sets are involved.

\section{Discussion}

The results presented above show beyond doubt that $\mathrm{B}$ chromosomes are responsible for a modification of chromosome association at meiosis in autotetraploid $L$. perenne such that more bivalents and less multivalents than expected are formed and furthermore that this is independent of p.m.c. 
chiasma frequency (see fig. 1). Although this tendency for association of pairs of chromosomes is increased, it is nevertheless not to the complete exclusion of multiple associations.

On the face of it, therefore, the overall effect of B chromosomes on pairing in this autotetraploids material is somewhat similar although, naturally, not as extensive as in interspecific hybrids of Lolium. In Lolium temulentum/perenne and Lolium remotum/perenne amphiploids association of homologous pairs at meiosis is almost complete with hardly any homoeologous pairing (Evans and Macefield, 1972, 1973; unpublished data). In such cases it is argued that structural differences between homoeologues would inevitably lead to some degree of preferential pairing anyway and that B chromosomes merely emphasise this in some way. In polyploids of closely related species where structural divergence is not cytologically apparent, but where cryptic differences are not ruled out, the overall pattern would not be expected to differ substantially from this. The present results are, however, from autotetraploid material and as such all four chromosomes should be structurally identical. Preferential pairing of chromosomes based on structural differences, however small, is therefore unlikely. It is true that in terms of gene content each set of four chromosomes can be separated into two identical pairs since all these tetraploids are derived from colchicine treatment of diploid material which was undoubtedly heterozygous. That differences of this nature could be a basis for B chromosome induced preferential pairing seems doubtful but cannot of course be ruled out.

The effect of B's must therefore be of a much more general nature than was hitherto assumed. It appears that both homoeologous and homologous pairing is modified to a certain extent but it is clear that the restriction on association of homologues is very much less than that of homoeologues. However, the functional basis of this B chromosome effect still remains a matter of conjecture.

\section{REFERENGES}

Bowman, J. G. 1974. Cytogenetic studies of species hybrids in Festuca and Loliums. Ph.D. Thesis, University of Wales.

BOWMAN, J. G., AND tHOMas, H. 1973. B chromosomes and chromosome pairing in Lolium perenne $\times$ Festuca arundinacea hybrid. Nature New Biol., 245, 80-81.

CROWLEY, J. G., AND REES, H. 1968. Fertility and selection in tetraploid Lolium. Chromosoma (Berl.), 24, 300-308.

EVANS, G. M., AND MACEFIELD, A. J. 1972. The suppression of homoeologous pairing by $\mathrm{B}$ chromosomes in a Lolium species hybrid. Nature Nerw Biol., 236, 110-111.

EVANS, G. M., AND MACEFIELD, A. J. 1973. The effect of B chromosomes on homoeologous pairing in species hybrids. I. Lolium temulentum $\times$ Lolium perenne. Chromosoma (Berl.), 41, 63-73.

EVANS, G. M., AND MACEFIELD, A. J. 1974. The effect of B chromosomes on homoeologous pairing in species hybrids. II. Lolium multiflorum $\times$ Lolium perenne. Chromosoma (Berl.), $45,369-378$

Hall, B. м. 1955. Binomial analysis of chromosome behaviour in hybrid plants. Proc. Penn. Acad. Sci., 29, 121-126.

SIMONSEN, ø. 1973. Cytogenetic investigations in diploid and autotetraploid population of Lolium perrene. Hereditas, $75,157-188$. 